\title{
新工科背景下地方高校应用化学专业特色建设的探索与实践 一以山东理工大学应用化学专业为例
}

邢令宝, 杨凯, 周朋飞, 李新进, 周晋, 王平, 禚淑萍*

山东理工大学化学化工学院, 山东淄博 255000

摘要: 本专业立足产业创新发展需求, 积极服务国家和区域经济发展, 发展精细化工、电化学工程和高分子化工特 色方向, 形成鲜明的以工为主、理工融合的厚基础、强实践应用型新工科人才培养特色。本文全面介绍了本专业在 专业定位、培养特色、师资队伍建设、实践教学体系建设和校企合作协同育人等方面的举措和成效。

关键词：应用化学；新工科；培养模式; 协同育人

中图分类号: G64; O6

\section{Exploration and Practice of Characteristic Construction of Applied Chemistry in Local Universities under the Background of Emerging Engineering Education: Taking Applied Chemistry Major of Shandong University of Technology as an Example}

\author{
Lingbao Xing, Kai Yang, Pengfei Zhou, Xinjin Li, Jin Zhou, Ping Wang, Shuping Zhuo * \\ School of Chemistry and Chemical Engineering, Shandong University of Technology, Zibo 255000, Shandong Province, China.
}

\begin{abstract}
The applied chemistry major is primarily associated with engineering and integration of sciences and technologies. Based on the needs of industrial development, this major actively serves the national and regional economic development, develops the characteristic direction of fine chemical industry, electrochemical engineering and polymer chemical industry, and forms the distinctive training characteristics of new engineering talents with a strong foundation and strong practical application. This paper comprehensively introduces the measures and results of the specialty orientation, training characteristics, construction of teaching staff, construction of practical teaching system and school-enterprise cooperation in education.
\end{abstract}

Key Words: Applied chemistry; Emerging engineering education; Training mode; Cooperative education

为了服务国家创新驱动发展和“中国制造2025”等一系列国家战略, 2017年2月, 教育部启动并 积极推进新工科建设, 先后发布 “复旦共识” “天大行动” 和 “北京指南” [1-4], 明确提出了 “新工 科”内涵指向, 要求加快建设高水平本科教育, 全面提高人才培养能力 ${ }^{[5]}$ 。以新工科理念为指导和牵 引，探索人才培养新模式，培养适应新工科发展需要的应用型人才势在必行。

山东理工大学应用化学专业2013年入选山东省高校品牌专业, 2016年入选山东省高水平应用型 专业群立项建设专业, 2018年入选山东省教育服务新旧动能转换专业对接产业项目立项建设专业, 2020年入选山东省一流本科专业建设点。近年来, 本专业积极探索实践应用化学专业新工科建设的

收稿: 2021-05-17; 录用: 2021-05-20; 网络发表: 2021-05-27

“通讯作者, Email: zhuosp@sdut.edu.cn

基金资助: 山东省本科教学改革研究培育项目 “新工科背景下基于政产教学研用的理工科协同育人机制研究与探索” 
人才培养模式综合改革 ${ }^{[6]}$, 形成了具有鲜明特色的应用型工科人才培养模式。

\section{1 综合改革, 系统推进专业特色优势建设}

\section{1 对接地方产业, 实现特色发展}

山东是化工第一大省, 学校地处的淄博市是化工产业核心区, 区域内化学化工、新能源、新材 料行业门类齐全、企业密集, 规模以上的化学化工类企业有近七百家, 化工产业群产值约 3 万亿, 其 中化工与新材料产值占比 $40 \%$ 以上, 对化学化工类应用型人才的需求很大。山东理工大学应用化学 专业前身为1996年成立的精细化工专业, 2004年设置应用化学本科专业。经过二十多年的学科发展 与积淀, 本专业教师在精细化学品和高分子化学研发方面取得了丰硕的科研成果, 发明了新型聚氨 酯化学发泡剂 “颠覆性技术”, 具有重大国际影响力, 专利转让费 5.2 亿元, 获山东省技术发明一等 奖、专利特别奖; 拥有 “教育部无氯氟聚氨酯泡沫材料工程研究中心” “山东省纺织化学品与染整 工程技术中心” ; 2014年以来, 本专业部分教师在电化学新能源技术、材料与器件制造方面取得一 系列科研成果, 获山东省自然科学一等奖等奖励, 依托 “山东省高校先进能源材料与催化重点实验 室” 的平台优势, 本专业开始建设电化学工程方向。近年来, 本专业持续建设精细化工、高分子化 工、电化学工程三个特色培养方向, 使专业更好地对接山东省新旧动能转换 “高端化工” 和 “新能 源、新材料” 产业的发展需求, 专业的特色优势愈加突显。

\section{2 强化师资建设, 专兼职结合建设 “双师型” 教师}

本专业实施教学与科研团队一体化建设, 建立并完善 “院-系-教研室-课程团队-课程负责人” 五级教学管理体制, 强化基层教学组织建设, 落实课程负责人制度, 定期开展教研和教学建设活动。 其中, 结合特色专业方向, 设置了精细化工、高分子化工和电化学工程三个教研室, 按照 “培养、 引进、共享” 并举的原则, 科学制定人才引进规划, 加大三个教研室的师资队伍建设力度。近 3 年, 精细化工方向引进优秀青年教师 4 人, 其中两人具有企业工作经验; 高分子化工方向引进优秀青年教 师 7 人, 其中 1 人直聘教授, 1 人直聘副教授, 两人具有企业工作经历, 依托该方向的新型聚氨酯材料 研究院获山东省 “干事创业好团队” 荣誉称号; 电化学工程方向引进优秀教师 9 人, 其中国家重点人 才工程专家 1 人, 1 人直聘副教授, 1 人具有企业工作经历, 培养山东省泰山学者青年专家 1 人。高水 平师资队伍建设产出了一批前沿学术成果, 学科水平显著提升, 化学和工程学均进入ESI全球排名前 $1 \%$, 为专业建设提供了有力支撑。

在教研室建设方面，各教研室设置负责人 1 人，下设课程团队，每个团队设置负责人 1 人，每门 课程设置负责人 $1-2$ 人, 由 $3-5$ 名教师共同负责一门课程的建设和教学。为满足教研室、课程团队和 课程负责人的建设需要, 本专业通过人才引进政策, 优化了教学团队的年龄结构、学历结构、知识 结构和学缘结构, 特别强化引进具有行业背景的青年教师, 并利用高校进修助课、企业实践锻炼、 科技特派员等途径加强 “双师型” 教师队伍培养。目前, 专业教师中已有 2 人赴地方挂职锻炼, 12 人 次赴东岳集团、齐鲁石化等企业进行实践锻炼, 4名教师赴山东重山光电材料股份有限公司等担任山 东省级科技特派员，15名教师赴山东金科力电源科技有限公司等担任 “科技副总” ， “双师型” 教 师的比例达到 $50 \%$ 以上。同时聘请知名企业的教授级高级工程师、高级工程师、高层管理人员及高 级技能人才担任产业教授、兼职教授和兼职教师, 加入专业教师队伍中, 指导学生专业实践。与东 岳集团、一诺威聚氨酯、兴鲁化工等企业签订校企联盟框架协议, 由企业出课题, 校企导师共同指 导学生进行毕业设计, 使毕业设计与企业生产衔接, 提高学生解决实际问题的能力, 也为毕业生的 就业提供有效渠道, 提升了应用型人才培养质量。聘请 20 名企业高级技术人员及管理人员为本专业 兼职教师, 从事专业实习、企业实践与技能训练、毕业实习、专业导论、专业技术前沿、创新创业 教育等课程教学, 提高专业实践教学质量。

\section{3 课程体系建设和课程教学改革}

本专业协同学科研究优势与专业特色建设, 贴近行业发展和地方产业优势, 加强特色课程建设, 
实现课程的高阶性、创新性和挑战性。建成 “聚氨酯绿色发泡虚拟仿真实验” 国家级一流课程 1 项、 “分析化学” “化工原理” 省级一流课程2门; 开设 “聚氨酯泡沫材料与应用” “化学电源工艺学” “有机氟化学” 等特色课程 8 门。

依托教育部无氯氟聚氨酯泡沫材料工程研究中心平台, 聚氨酯材料教学科研团队建设了 “聚氨 酯材料与应用” 特色课程和 “聚氨酯绿色发泡虚拟仿真实验” 虚拟仿真实验项目, 积极打造一流仿 真实训平台。该课程既能加强应用化学专业学生的培养特色, 又能紧密对接山东省聚氨酯产业优势。 在该课程授课过程中, 除本校教师进行理论讲授外, 还邀请一诺威、德信联邦等聚氨酯行业领域公 司兼职教师进行授课, 使课程内容更加丰富、更加贴近行业发展。本课程团队也积极反哺相关企 业, 一诺威、德信联邦等企业均使用 “聚氨酯绿色发泡虚拟仿真实验” 和仿真实训平台进行技术岗 位培训, 并给予肯定评价。

精细化工方向与东岳集团联合设立 “氟硅材料班” , 开设 “有机氟化学” “有机硅化学与工艺” 等特色课程, 组建校企合作教研室。通过与企业兼职导师共同制定课程标准、教学大纲等课程材料, 优化教学内容, 使学生既能掌握课程理论知识, 也能针对企业难题共同出谋划策。在课程讲授中, 采取 “案例式+启发式” 教学方式, 理论与实践相结合的教学思想, 积极培养学生分析、解决实际生 产问题的能力。本课程加大实践教学环节, 通过 “学校实验 + 企业实践” 的模式, 增加学生的实践经 验, 拓宽学生的视野维度。本课程团队成员定期参与东岳集团实践锻炼, 持续开展课程建设, 满足 应用型人才特色培养需要。

电化学工程方向的课程建设注重将理论、科研与实践有机融合, 开设 “化学电源工艺学” “锂 离子电池” 特色课程, 精选具有多层次、前沿性和创新性的优质案例, 让学生掌握前沿的科研方法 和专业技术。为更好地实现理论与实践的结合, 学院聘请企业工程师开设讲座, 融入工作要求和岗 位技能, 通过深入维动新能源、金科力电源等周边地区具有代表性的新能源制造企业进行一线生产 实习, 建立产学研一体化人才培养体系, 培养基础知识扎实, 实践动手能力强, 综合素质高的应用 型人才。

\section{4 实践教学体系建设}

针对新工科对学生实践能力的高要求, 为了提升应用化学专业学生的实践能力, 专业构建了 “四 模块、三层次、两互动、一体化” 实践能力培养体系(如图1所示)。 “四模块” 指培养学生的动手实 验、科学研究、工程设计和创新创业四种实践能力; “三层次” 指由基础到应用的课内实验建设、 工程实训建设和企业实习建设, 由理论向实践、由课堂向产业逐层加深; 通过校企、师生、生生之 间的 “两互动”，建立了 “一体化” 的实践教学体系。

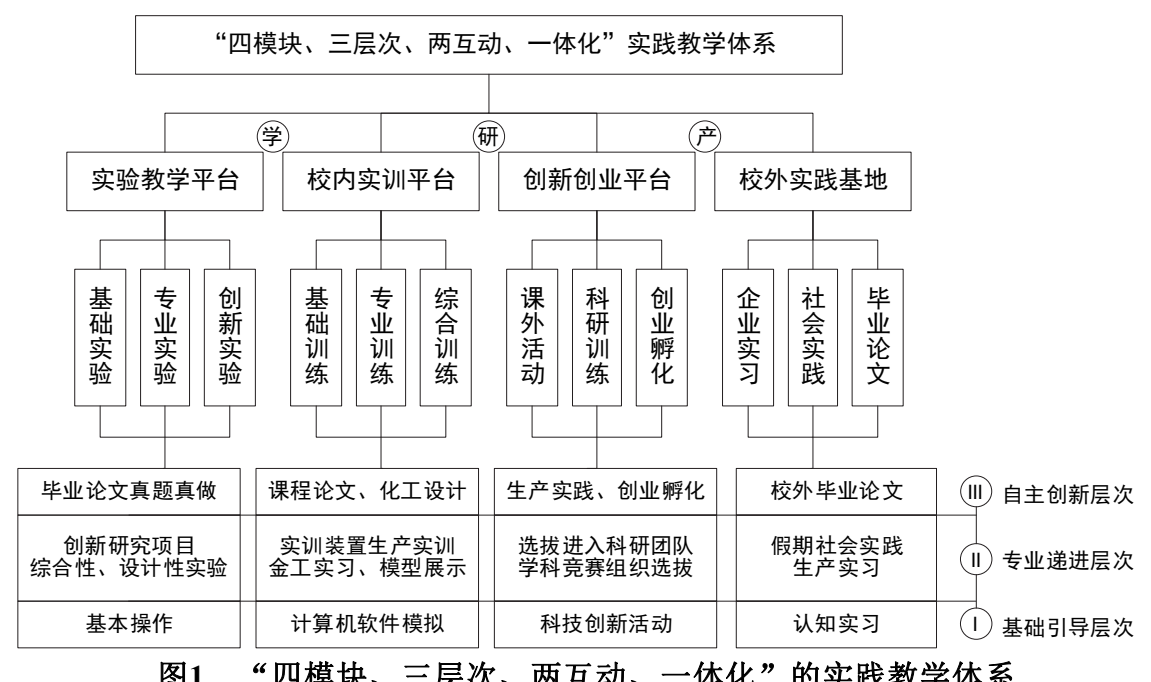

图1 “四模块、三层次、两互动、一体化” 的实践教学体系 
实验教学方面, 以培养学生的创新精神和实践能力为目标 ${ }^{[7]}$, 强化综合性、设计性和创新性实 验项目的开设, 并按照三个特色培养方向分别设置。例如, 结合行业生产和产品性能, 在高分子化 工方向开设了 “无氯氟硬质聚氨酯泡沫材料制备与性能检测” “高回弹软质聚氨酯泡沫材料制备与 性能检测” “聚砜微滤膜制备及其对墨水的截留测定” “聚醚砜/磺化聚砜疏松纳滤膜染料分离” 等 实验项目; 结合企业生产新工艺和新技术，在精细化工方向开设了 “抗氧剂双酚A的制备” “增塑剂 邻苯二甲酸二丁酯的制备” “聚氨酯乳液涂料的制备” “香蕉水的制备” 等实验项目; 结合企业生 产实际, 在电化学工程方向与山东金科力电源科技有限公司合作开设了 “ $\mathrm{Pt} @ \mathrm{C}$ 复合催化剂的制备及 其电催化氧还原性能” 实验项目, 开发了新型质子交换膜燃料电池催化剂, 降低贵金属Pt含量; 与 山东维动新能源股份有限公司合作开设了 “模板法制备介孔二氧化硅及其在锂硫电池中的应用研究” 实验项目, 开发了新型介孔二氧化硅的硫载体，提高载硫量。

深入强化认识实习和生产实习。近年来, 本专业与精细化工行业的知名企业齐鲁石化、德川化 工、东岳集团等, 高分子化工行业的知名企业蓝星东大、英科医疗、一诺威聚氨酯、德信联邦等, 电化学及电池企业维动新能源、金科力电源等进行紧密的产学研合作, 建设稳固的实习实践基地 20家(表1)。2018年通过与临淄区政府签订 “战略合作协议” , 进一步推进企业实习基地的建设。现 有实习基地能够涵盖精细化工、高分子化工和电化学等多个行业, 每年可满足500名左右的学生同时 参加生产实习和认识实习, 实现了实习环节对学生的全覆盖。

\section{5 校企深度合作, 创新应用型人才培养新模式}

专业与东岳集团在科学研究、技术培训、职工进修、本科生实习等方面有长期的合作基础, 2014年 双方签署校企联合培养协议, 合作培养 “氟硅高分子材料” 应用型人才, 实行 “ $2+1.5+0.5$ ” 的联 合培养学制, 共建课程, 组建校企合作教研室, 制定培养方案和课程标准, 加大实践学分比例, 完

表1 应用化学专业实习基地名单

\begin{tabular}{|c|c|c|c|c|}
\hline 序号 & 基地名称 & 产业类别 & 建立时间 & 接纳人数 \\
\hline 1 & 中国石化齐鲁石油化工公司 & 精细化工 & 2014 & 40 \\
\hline 2 & 山东一诺威聚氨酯股份有限公司 & 高分子化工 & 2014 & 20 \\
\hline 3 & 山东英科医疗用品股份有限公司 & 高分子化工 & 2014 & 40 \\
\hline 4 & 山东德信联邦化学工业有限公司 & 高分子化工 & 2014 & 20 \\
\hline 5 & 山东德川化工科技有限责任公司 & 精细化工 & 2019 & 40 \\
\hline 6 & 山东金科力电源科技有限公司 & 电化学工程 & 2016 & 20 \\
\hline 7 & 山东兴鲁化工股份有限公司 & 精细化工 & 2018 & 20 \\
\hline 8 & 山东新华隆信化工有限公司 & 精细化工 & 2018 & 20 \\
\hline 9 & 山东东岳化工有限公司 & 精细化工 & 2014 & 40 \\
\hline 10 & 维动新能源股份有限公司 & 电化学工程 & 2020 & 20 \\
\hline 11 & 山东荣昌制药有限公司 & 精细化工 & 2019 & 30 \\
\hline 12 & 淄博齐翔腾达化工股份有限公司 & 精细化工 & 2018 & 20 \\
\hline 13 & 山东鸿运工程设计有限公司 & 精细化工 & 2019 & 20 \\
\hline 14 & 山东金诚石化集团有限公司 & 精细化工 & 2014 & 40 \\
\hline 15 & 淄博釒泰石化有限公司 & 精细化工 & 2018 & 40 \\
\hline 16 & 山东金城柯瑞化学有限公司 & 精细化工 & 2014 & 40 \\
\hline 17 & 山东汇智工程设计有限公司 & 精细化工 & 2014 & 20 \\
\hline 18 & 山东北方淄特股份有限公司 & 精细化工 & 2014 & 40 \\
\hline 19 & 山东蓝帆化工有限公司 & 精细化工 & 2016 & 40 \\
\hline 20 & 山东蓝星东大有限公司 & 高分子化工 & 2014 & 40 \\
\hline
\end{tabular}


善了包括氟涂料加工应用、氟塑料加工应用、化工公司技术实验室等在内的多处合作实践基地, 实 践类课程教学采用现场授课。依托校城融合, 投资 80 余万元建成校内氟硅高分子材料专业实验室及 创新实践平台, 成功探索了 “校内学习, 企业见习, 双向选择-签订订单, 协作培养, 生产实训-双导 师制, 融入企业, 培训就业” 的校企联合 “订单式” 培养模式; 建立 “企业命题、双师指导、企业 检验、成果转化” 创新实践机制; 在实习、新产品研发、创新研究立项及毕业设计环节均实施校企 双导师指导 ${ }^{[8]}$, 全程做到专业性与实用性的结合, 开拓校企合作协同育人的新模式。经过两期的探 索实施, 目前已稳定建立了人才共享、设备共享、技术共享、文化互补、管理互通的校企合作新机 制, 实现学校教育质量、企业人才需求和学生就业发展的三方共赢局面。已在东岳集团华夏新材料 有限公司技术部管控公用工程岗位任职的张云岭回顾作为第一批 “山理东岳人” 时说： “联合培养 增设的课程对自己专业能力提升起到了很大的作用, 初入职场时与一般应届毕业生相比, 对工作环 境的适应性强了很多, 对工作类型的选择针对性增强, 自己的兴趣与岗位能够充分结合。”截止到 目前, 该项目已经向东岳集团乃至整个氟硅行业输送了一批符合企业要求的 “氟硅材料” 专业应用 型人才。“校企合作提升化学工类专业本科生实践创新能力的系统设计与实施” 荣获山东省第八届 高等教育省级教学成果二等奖。

\section{2 人才培养成效}

依据《化学化工学院毕业生跟踪反馈与社会评价工作管理办法》 《化学化工学院毕业要求达成 评价与持续改进实施办法》, 专业建立了完善的毕业生跟踪反馈和社会评价机制, 定期对专业人才 培养质量进行评价。跟踪调查的主要内容见表2。

通过收集、整理和分析来自往届毕业生、用人单位、行业协会及其他社会机构的信息和外部评 价表明, 用人单位对本专业毕业生的道德素养、知识结构、专业技能、团队协作等能力都较为满意, 综合评价优秀率达 $93 \%$; 在全国各大高校继续深造的本专业毕业生, 在思想品德、专业基础、研究 能力方面, 也都受到了就读学校的高度评价。近 3 年, 本专业毕业生就业率均保持在 $90 \%$ 以上, 毕业 生工作与专业相关程度达到 $95.6 \%$, 毕业生对就业职业满意度达到 $96 \%$, 校友满意度 $97 \%$ 。基于毕业 生在工作单位的健康发展和良好影响, 多家用人单位如金诚石化、一诺威聚氨酯、英科医疗、鲁华 泓锦来校设立了奖助学金。

表2 毕业生培养质量跟踪评价调查情况表

\begin{tabular}{ccc}
\hline $\begin{array}{c}\text { 用人单位调研主题 } \\
\text { (培养效果与行业需求契合度) }\end{array}$ & $\begin{array}{c}\text { 应届毕业生调研主题 } \\
\text { (培养过程满意度) }\end{array}$ & $\begin{array}{c}\text { 毕业五年毕业生调研主题 } \\
\text { (培养效果与职业需求契合度) }\end{array}$ \\
\hline 专业知识 & 教学方法 & 知识结构 \\
实践能力 & 教学形式 & 实践能力 \\
创新设计能力 & 教材 & 创新能力 \\
独立解决问题能力 & 实验环节效果 & 研究能力 \\
研究能力 & 实践环节效果 & 运用先进工具能力 \\
运用先进工具能力 & 人文素质培养 & 法律法规和职业道德 \\
法律法规和职业道德 & 法律意识职业道德 & 安全和环保意识 \\
安全和环保意识 & 课程体系安排 & 工程项目管理能力 \\
工程项目管理能力 & 沟通与交流能力培养 & 团队合作能力 \\
团队合作能力 & 创新创业教育 & 沟通与交流能力 \\
沟通能力 & 课程内容 & 自我发展能力 \\
自我发展能力 & 课外活动 & 所从事的职业 \\
\hline
\end{tabular}




\section{3 结语}

本专业将继续全面落实 “以本为本、四个回归” ，坚持 “立德树人” ，把人才培养作为专业建 设的重中之重, 把思想政治教育贯穿人才培养全过程, 以新工科建设为重要抓手, 持续深化工程教 育改革。依托无氯氟聚氨酯泡沫材料工程研究中心等学科平台, 继续加强实践教学平台建设, 为实 习实践、创新竞赛等提供优质教学条件, 提升学生创新创业和实践能力; 在校企合作和协同育人工 作基础上, 深度挖掘企业教学资源, 课程教学与产业相结合, 将产业技术最新成果、行业发展最新 要求引入教学过程, 持续推进校企深度合作, 全面创新协同育人机制。

\section{参 考 文 献}

[1] 教育部高等教育司关于开展新工科研究与实践的通知. [2017-02-20]. http://www.moe.gov.cn/s78/A08/tongzhi/201702/t20170223_297158.html

[2] “新工科”建设复旦共识. [2017-02-18]. http://www.moe.gov.cn/s78/A08/moe_745/201702/t20170223_297122.html

[3] “新工科”建设行动路线(“天大行动”). [2017-04-08]. http://www.moe.gov.cn/s78/A08/moe_745/201704/t20170412_302427.html

[4] 新工科建设指南(“北京指南”). [2017-06-09]. http://www.moe.gov.cn/jyb_xwfb/gzdt_gzdt/moe_1485/201706/t20170610_306699.html

[5] 教育部关于加快建设高水平本科教育全面提高人才培养能力的意见. [2018-10-08].

http://www.moe.gov.cn/srcsite/A08/s7056/201810/t20181017_351887.html

[6] 张树永, 朱亚先, 霍冀川, 宋丽娟, 徐华龙, 郑兰䔉. 大学化学, 2020, 35 (10), 6 .

[7] 张树永, 朱亚先, 张剑荣. 大学化学, 2018, 33 (10), 1.

[8] 温永红, 王世颖, 高洪涛, 詹天荣. 大学化学, 2020, 35 (9), 7. 